\title{
Chapter 7 \\ How Inclusive Institutions Enforce \\ Exclusive Immigration Rules: Mainstream \\ Public Service Provision \\ and the Implementation of a Hostile \\ Environment for Irregular Migrants \\ Living in Britain
}

\author{
Reinhard Schweitzer
}

\subsection{Introduction}

Migrant irregularity is not a new phenomenon but has long characterised the mobility or residence of many people coming to Europe in search of better employment opportunities or after fleeing violence and persecution elsewhere (Black 2003). What changed are the regulatory measures through which the governments of receiving states try to undermine irregular migration and residence. Control and surveillance have not only been intensified but also gradually extended from the external boundaries to the interior of the state and society (Balibar 1998). In order to effectively constrain irregular migrants' ${ }^{1}$ opportunities for participation and their access to various rights and services, immigration law and policy penetrate ever more spheres of everyday life and social interaction (Broeders and Engbersen 2007; Cvajner and Sciortino 2010; Garcés-Mascareñas 2015; Schweitzer 2018a; Spencer and Hughes 2015; Van der Leun 2006). This policy trend towards a selective prevention of integration is particularly visible in the UK, where the government officially aims to 'create here in Britain a really hostile environment for illegal migration' (Kirkup and Winnett 2012).

In this chapter I am particularly interested in the implementation of such policies, which hinges on the capacity and willingness of a growing number and variety of actors to effectively exclude certain categories of foreigner (Guiraudon and Lahav 2000; Jordan et al. 2003). In everyday practice, this often entails the formal

\footnotetext{
'I use the terms 'irregular migrants' and 'migrants in irregular situations' interchangeably; both refer to foreigners who currently lack a formal right of residence in the country where they live.
}

\footnotetext{
R. Schweitzer $(\bowtie)$

University of Vienna, Vienna, Austria

e-mail: reinhard.schweitzer@univie.ac.at
} 
or informal consolidation of an external logic that demands the exclusion of a person - qua irregular immigrant - with various internal logics that require his or her (partial) inclusion - as a local resident, worker, patient, student, service recipient and so on. Much of this constant renegotiation of irregular migrants' inclusion and exclusion takes place within the institutions of the liberal welfare state (Bommes and Geddes 2000), which face and often struggle to meet the most fundamental needs and legitimate claims of irregular and regular residents.

Protecting the welfare state against proclaimed 'health tourists' and 'benefitscrounging foreigners' has become a routine justification for restrictive policies towards actual or potential newcomers. Their exclusion is thereby argued to be necessary in order to ensure adequate service delivery for the deserving, which is also critically discussed by Hinger (2020) in this volume. At the same time, public welfare is also 'a major factor driving the incorporation of immigrants $[\ldots]$ because it follows a logic of inclusion: failure to grant social rights to any group of residents leads to social divisions, and can undermine the rights of the majority' (Castles 2004, p. 216). The provision of mainstream public services to irregular migrants thus involves the intertwining of integration and disintegration policies, and its analysis highlights the fact that the very concept of 'integration' comprises two empirically different but intrinsically related aspects: not only the 'integration' of a particular individual or group into society but also the 'integration' (or cohesion) of that same society (Treibel 2015). What remains unacknowledged in most public, political and scholarly debates around integration is that both of these aspects ultimately hinge on the same connections and interactions between people and institutions, and thus cannot be regulated as if they were two entirely separate processes (Schweitzer 2017a). As argued in the introduction to this volume (Collyer et al. 2020), policies aimed at preventing the integration of certain individuals thus also contribute to the disintegration of society as a whole. One way of doing this is by undermining the inclusiveness of mainstream welfare provision.

Among the institutional and individual actors who participate in the everyday negotiation of irregular migrants' (dis)integration are street-level bureaucrats who work within public welfare systems (Lipsky 1980). As doctors, school administrators or welfare officers, they increasingly (have to) implement certain aspects of the immigration rules and are thereby 'often placed in the awkward position of triggering the law's force when they come face to face with an 'unlawful' person' (Park 2013, p. 12). At the same time, their individual agency and decisions must also be seen as structurally embedded; within not only a political environment that can encourage hostility towards certain groups but also the much more specific institutional contexts within which they work.

Drawing on key theoretical insights from organisation studies, this chapter looks at how various local institutions providing different kinds of mainstream public services in London have responded to the external demand for their participation in immigration control. One crucial component and apparent commonality within these organisational responses is the rather spontaneous emergence of specialised subdivisions that deal specifically with migrant irregularity. My analysis shows that it is through them, that the politics of (dis)integration becomes institutionalised 
within the British welfare system. On the one hand, this modification allows the organisation to more effectively fulfil its actual function for society by shielding its core professional staff from contradictory logics and demands (e.g. doctors from checking the passports of their patients). On the other hand, however, the structural adjustments have also helped to systematically undermine the necessary firewall between immigration enforcement and public service provision and rendered this overlap less visible to the general public and less exposed to internal and external resistance or contestation.

\subsection{A 'Hostile Environment' for Just One Category of Residents?}

Many Western states increasingly address the issue of irregular migration through policies of internal control, often by restricting the access of unlawful residents to employment, housing, healthcare or other services (Broeders and Engbersen 2007; Guiraudon and Lahav 2000; Lahav and Guiraudon 2006; Spencer and Hughes 2015; Squire 2011; Van der Leun 2006). Facing a growing permeability of its external borders, it is argued, the state 'raises a protective wall of legal and documentary requirements around the key institutions of the welfare state' (Broeders and Engbersen 2007, p. 1595). As a way to regain control and increase the effectiveness of these policies, governments thereby partly shift the burden of enforcing immigration regulations to a range of actors beyond the level of the nation-state and hitherto detached from its immigration regime. This includes not only employers and transport companies but also local authorities and mainstream welfare services. The British government's effort to create an 'environment' that will 'make it [...] more difficult for illegal immigrants to live in the UK' (Home Office 2013, p. 2) also critically depends on the participation of such actors. Concrete policy measures include an obligation for private landlords and certain National Health Service (NHS) staff to check the immigration status of their tenants and patients, a prohibition on banks opening accounts for irregular migrants and new powers to check driving licence applicants' immigration status and revoke the licences of those who have overstayed their visa. This criminalisation of ordinary interactions with unlawful residents generates uncertainty among public servants and furthers discrimination against nonEuropean (-looking) immigrants and even citizens (MRN 2015; Spencer and Hughes 2015).

Walsh (2014, p. 242) has described this development as deputisation, which he generally defines as 'the activation and empowerment of certain individuals to participate in preventing and controlling legal transgressions'. He thereby distinguishes deputisation from responsibilisation - whereby such participation is encouraged but voluntary - and autonomisation - which happens spontaneously or even against the will of the authority. As I will show, some welfare workers are obliged or encouraged to base their actions or decisions regarding a client on the immigration status 
of the latter, while others are being specifically prevented or discouraged from doing so (which I will refer to as shielding).

In practice, only those actors who are not shielded from the logic of immigration control can be expected to exclude irregular migrants from a particular site or service. If the same actors are also required or encouraged to share their knowledge of someone's irregularity with the responsible state authority - in this case the Home Office (HO) - they effectively become part of the deportation regime. Such information sharing, whether systematic or sporadic, indicates the lack of a firewall, i.e. any mechanism or rule that prevents individuals or organisations from passing this kind of information to the immigration authorities, thereby effectively limiting the reach of internal immigration control (Carens 2013; FRA 2013; OHCHR 2014). Seen from a system-theoretical perspective, a firewall constitutes one way of ensuring the independent and thus effective performance of the various (other) subsystems which, together, make up a modern, functionally differentiated, society (Luhmann 1982, 1995; Walzer 1983).

An understanding of society as 'a plurality of specialized subsystems that have their own set of symbolic codes, leading values, operational programs and regulative means' (Cvajner and Sciortino 2010, p. 392; see also Sciortino 2000) thus helps the analysis of how immigration policies work (or not) within specific institutional spheres. It means taking into account the different organisational cultures and logics, shared norms, professional identities, values and codes of conduct that guide the actions and shape the interests of the people working in these societal subsystems, which are only recently becoming part of the immigration regime (Jordan et al. 2003). It is thereby very suitable to identify the various challenges that arise where the logic of (internalised) immigration control - fundamentally based on the distinction between regular and irregular status - intersects with other logics, such as those according to which doctors treat their patients, social workers try to protect vulnerable clients against destitution, or universities select prospective students.

It has been shown that policies of internal control encounter both support and resistance on the part of other local residents, the wider public, specific interest groups and civil society organisations, as well as individual professionals, civil servants and local government officials (Broeders and Engbersen 2007; Ellermann 2006; Guiraudon and Lahav 2000; Van der Leun 2006). Coinciding and conflicting interests can even be present simultaneously within the same institution, and a lot depends on individual motivations and perceptions (Perna 2018). Particularly where rigorous exclusion would create significant costs or contradictions, however, migrant irregularity is often more or less routinely accommodated within existing organisational structures and institutional logics (Schweitzer 2018b). Conceptually but also empirically, this implies a certain level of recognition and incorporation of formally irregular migrants and can thus not only make visible but also further their claims for social membership (Chauvin and Garcés-Mascareñas 2014; Hellgren 2014; Schweitzer 2017b). The next section theorises the underlying negotiation processes in more detail to better understand the crucial role that local institutions and individual street-level bureaucrats (can) play within the broader politics of (dis) integration. 


\subsection{Public Sector Organisations and Street-Level Bureaucrats as Local Mediators of Competing Institutional Logics}

The provision and allocation of public services in general and their extension to irregular migrants in particular, always involves a series of political decisions regarding the exact circumstances under which to offer, deny or require payment for particular services. These political decisions are then translated into legal frameworks and policies which, in turn, have to be implemented 'on the ground'. As argued by Boswell (2007, p. 83), neo-institutional theories make two crucial assumptions in relation to the role that liberal institutions (can) play for policy implementation - firstly, that they 'have sufficient independence from the political system and rival administrative agencies' and, secondly, that 'the actors within these institutions operate according to interests and norms that are at variance with those predominating politics or rival agencies'. As I will show, both assumptions are highly relevant for understanding the involvement of public welfare institutions in the implementation of immigration control or even enforcement.

Access to services depends not only on the more or less explicit laws and regulations that circumscribe formal eligibility but often also on a case-by-case assessment by individuals who either administer or provide them to the population. In trying to control immigration through these local actors, the government is exploiting the fact that their role often already involves some form of gate-keeping. As famously argued by Lipsky $(1980,1987)$, this requires a significant level of discretion on the part of street-level bureaucrats, who have to be able to deal with the irregularities that more or less routinely arise in their daily encounters with service users and often require customised solutions. According to him, it is thus their particular position within certain organisations - characterised by 'relatively high degrees of discretion and relative autonomy from organizational authority' - that 'regularly permits them to make policy' (Lipsky 1987, p. 121). While these microlevel decisions can have a significant impact on individual lives, they are difficult to control by state authorities.

This highlights the ambivalent relationship of street-level bureaucrats with the state (which employs them) and the local population (for whom they work). As bureaucrats, they have to adhere to a set of official rules, follow formal procedures and apply established criteria, all of which circumscribe their possible actions towards their clients. As professionals, they are 'expected to exercise discretionary judgement in their field [of expertise]' and to be able to deal with a broad range of individual cases and human circumstances (Lipsky 1987, p. 121). The balance between these two aspects of their job depends on their position within the organisation (as well as that of the organisation vis-à-vis other agencies) and whether their specific role mainly involves administrative or professionalised tasks. In modern bureaucracies, the various organisational roles are generally separated from the person who performs them, which 'has resulted in a capacity to constitute agency and 
identity in more segmented and piecemeal ways, according to the demands of distinct institutional realms' (Webb 2006, p. 34).

Lipsky (1987) has also shown that street-level bureaucrats tend to refuse to comply with rules which they perceive as contrary to their own professional or organisational role. A particularly strong professional status - like that of a doctor or teacher - and the absence or inefficiency of sanctioning mechanisms thereby make non-compliance even more likely. This not only enables bureaucrats to effectively deal with exceptional cases and irregular situations but also allows them to exercise political agency by contesting or circumventing the implementation of a particular policy or at least re-interpreting certain aspects of it. All this does not mean, however, that their decisions are taken in some sort of vacuum.

Another important insight stemming from organisation studies is that organisational actors and their actions are always embedded within certain (although sometimes multiple) institutional logics (Besharov and Smith 2013; Lindberg 2014; Meyer and Rowan 1977; Reay and Hinings 2009; Scott 2001). These provide 'a coherent set of organizing principles for a particular realm of social life' (Besharov and Smith 2013, p. 366) and underpin 'the belief systems and related practices that predominate in an organizational field' (Scott 2001, p. 139), such as healthcare or social work. While organisational action within any such field is normally guided by only one institutional logic, several other logics constantly tend to coexist, compete with and sometimes replace the dominant one as the guiding principle - a process that also helps to explain institutional change (Lindberg 2014; Scott et al. 2000). Besharov and Smith (2013, p. 365) have argued that the concrete 'implications of logic multiplicity depend on how logics are instantiated within organizations'.

What is particularly crucial to my analysis here is that organisations can actively reduce the risk of competing logics generating internal conflict through structural adjustments that either make compliance with a new set of rules more likely or noncompliance less visible. According to Besharov \& Smith (2013, p. 376), this can be achieved "by developing a cadre of organizational members who are less strongly attached to particular logics or by buffering members from the influence of those logics'. In contrast to this, Reay \& Hinings (2009, p. 645) posit that 'actors guided by different logics may manage the rivalry by forming collaborations that maintain independence but support the accomplishment of mutual goals'.

On the one hand, both of these accounts recognise that, in order to have an actual effect on organisational practice, institutional logics have to be enacted by individual actors working within the organisation (Lindberg 2014). On the other, they reflect one of the central premises of neo-institutionalism, which posits that organisations constantly strive for legitimacy and, in order to be seen as legitimate by their environment, need to effectively fulfil their ascribed function (Meyer and Rowan 1977; Scott 2001). Some structural elements are thereby incorporated because of their resonance with certain institutionalised myths that reflect what their environment sees as proper functioning and successful performance, even if, in practice, they do not help or even hinder the efficient realisation of the central goals of the organisation (Meyer and Rowan 1977). 
Under this premise it can be argued that, from the perspective of public service providers, the supposedly clear-cut and binary distinction between regular and irregular migrants represents such an institutionalised myth. It is incorporated into their organisational field not because it makes practical sense but because providing services to unlawful residents would undermine the sovereignty of the state or at least the efficiency of its immigration system. Where this logic requires irregular migrants to be denied access to a particular service, some members of the organisations that provide it will become responsible for exercising a form of immigration control and thereby enact a new institutional logic within these organisations. While probably seen as legitimate or even necessary by a majority of the population, this may, for various reasons, contradict service providers' own individual interests, professional ethics or the particular logic that dominates the institutional setting in which their actions and decisions are embedded. The underlying moral and political conflicts are thus not solved but merely delegated to the implementing agency, where they have to be managed through 'the actions of micro-level actors [...] developing localized structures and systems that [enable] day-to-day work', as Reay $\&$ Hinings (2009, p. 630) have shown.

In the following section, I use these theoretical insights to explain a crucial aspect of how different organisations (namely hospitals, universities and local welfare departments) have responded to the increasing pressure to incorporate the exclusionary logic of immigration control into their own organisational structures and operations. The empirical data were collected between July 2014 and February 2015 as part of my $\mathrm{PhD}$ research in London, where I conducted a total of 46 semistructured interviews with migrants in irregular situations, NGO practitioners and street-level bureaucrats working in organisations that provide public healthcare, education and social assistance to local residents. All interviews were audiorecorded, fully transcribed and anonymised, and then thematically coded using the software NVivo; details of those quoted here are provided at the end of the chapter.

\subsection{Organisational Responses to Everyday Bordering Within Different Institutions}

\subsubsection{Everyday Bordering Within the Hospital}

Since 2004, when the UK government introduced the Overseas Visitors Hospital Charging Regulations, all foreigners who are not 'ordinarily resident' ${ }^{2}$ are categorised as 'Overseas Visitors' and as such, in principle, should be charged the full cost of any NHS hospital treatment they incur ${ }^{3}$ (da Lomba 2011; DoH 2013a). However,

\footnotetext{
${ }^{2}$ A status not explicitly defined in law but conditional, among other things, on lawful residence. ${ }^{3}$ Until 2004 they were entitled to free treatment after 12 months of, even irregular, residence in the country. The general charging regulations do not apply to Accident \& Emergency (A\&E) services, nor to the diagnosis and treatment of certain communicable diseases.
} 
the Department of Health (DoH) (2013b, p. 55) also makes very clear that, where treatments are considered 'urgent' or 'immediately necessary', they cannot 'be delayed or withheld pending payment', which gives significant weight to the medical assessment of the patient's condition. The discretion in taking these decisions comes with the very nature of the medical profession and unavoidably plays a significant role within every healthcare system. In the British case, however, where the treatment of 'Overseas Visitors' is officially defined as 'urgent' if it 'cannot wait until the person can be reasonably expected to return home' (DoH 2013a, p. 43), clinicians are also required to take into consideration the likelihood and possible duration of a patient's stay in the country (da Lomba 2011). Both directly depend on immigration status and are particularly difficult to assess in the case of irregular migrants, who are estimated to represent more than 60 per cent of the total 'chargeable population'4 (DoH 2012, 2013a).

Upon registration with a family doctor - to which they are legally entitled 'Overseas Visitors' hold exactly the same NHS card as any other NHS patient. This lack of specification of the holder's entitlement beyond primary and emergency care is a remainder of the system's universalistic origins and makes it difficult for hospitals to comply with their legal obligation 'to determine whether the Charging Regulations apply to any overseas visitor they treat' (DoH 2013a, p. 16) and recover the costs of any services they have delivered. At the hospital level, this discrepancy has created the need for a particular kind of administrative personnel - that is, a new organisational role - responsible for identifying who is chargeable. It is not surprising that, from the perspective of these so-called Overseas Visitors Managers (OVMs), one of the major problems of the NHS is that people too easily slip through the system, as the head of the responsible department at a medium-sized London hospital, explained to me:

the reason why they can slip through the system [...] is that anybody can obtain a national health number. [...] All they do, actually, is go to a GP, ask the GP to register them, and the GP therefore registers them and gives them an NHS number (Interview 2).

This reflects what according to one of the GPs I interviewed has become a common view within the NHS - that GP registration is seen 'as an underground route to secondary care' (Interview 3). But the OVM also acknowledged that even though 'by law, we have to check every new patient that comes into the hospital, [...] that is physically impossible, and it would cost an absolute fortune' (Interview 2), which is why, in practice, her department focuses mainly on the areas of women's health and orthopaedic care. Asked for the reasons behind this selection, she explained that it was 'principally because a lot of people come over here to give birth, and orthopaedic because it is quite an expensive area'; however, she also mentioned that 'we also have good staff who we could encourage to participate in those sections' (Interview 2 ). The exact meaning of this comment became clear to me when she later received

\footnotetext{
${ }^{4}$ The remaining 40 per cent are temporary visitors who notably include British citizens residing in another country.
} 
a phone call from the hospital's maternity ward notifying her about the arrival of a new patient, after which she explained to me:

In that case I would be very, very surprised if that person is entitled to NHS care, so we will go up to see her; we will ask her to see her documentation. I mean, she is on the labour ward, so I don't think that's the right time to ask, personally, so I will probably leave that and go after she has given birth. [...] It could be that she has got Leave to Remain. It may have been that she just came to see her family and just came down... you know, we cannot guarantee that. But this case we would class as suspicious (Interview 2).

Her account is a good example of how 'NHS staff often have to make assumptions about government [immigration] policy in their work', as Wind-Cowie and Wood (2014, p. 55) have noted; however, it also highlights the level of direct implication of her role in the actual enforcement of this policy, as well as the very subtle kind of discretion (as to who, when and how to check) that she employs in carrying out this function. Asked what happens in case a patient is unable to prove their entitlement or to produce a valid passport, my interviewee replied that

[t]hey have to produce their passport, which [...] will have a stamp in it, so that will show whether that person is entitled or not. From there, once we have identified her, we will raise an invoice. If she doesn't pay... again, we have to treat this patient but, if she doesn't pay then, in three months' time, that invoice will be going over to... we will inform the DoH $[\ldots]$ who then filter it and would let the HO know (Interview 2).

She thereby refers to a formal mechanism that very explicitly institutionalises the overlap between the interest of the hospital (in recovering the costs) and that of the immigration authority (in controlling immigration), by allowing

NHS bodies [... to] share non-medical information with the Home Office, via the Department of Health, on those with a debt of $£ 1,000$ or more once that debt has been outstanding for three months, with a view to better collect debts owed. The Home Office can then use that information to deny any future immigration application to enter or remain in the UK that the person with the debt might make (DoH 2013a, p. 63).

Notably, this information exchange does not require patients' explicit consent although they 'should' be made 'aware of the potential immigration consequences of not paying' (ibid.) which, for Wind-Cowie and Wood (2014, p. 13) 'poses an enormous ethical challenge for healthcare professionals and the NHS as a whole'. While the OVM I interviewed clearly perceived her role within the hospital and the NHS as one of control, she did not readily acknowledge that what she is controlling is immigration. Instead, when I asked her how she felt about 'quasi' acting as an immigration officer, her answer was ambiguous:

I don't think we do. I mean, if you were an immigration officer you would be informing immigration [authorities], you would be informing the borders agency. And we will work with the borders agency, and we will let the... DoH know of patients who owe us money. Now, it's the $\mathrm{DoH}$ that then would possibly pass that information to the $\mathrm{HO}$, and it would then put it on a system so that perhaps these people... but they are not traced here! It's normally the people who try to get back [into the UK] whom we are stopping. [...] So personally, I don't think that we work as an immigration officer... maybe wrongly, perhaps we do (Interview 2). 
She clearly emphasises that she and her team are not targeting immigration offenders but patients who owe the hospital money. At the same time, however, she is aware that her role - together with the mechanism of letting the HO know - plays a decisive part in the government's broader efforts to limit irregular residence - and unwanted immigration more generally:

I believe that that is a deterrent and I think what it is doing is stopping a lot of people getting their Leave to Remain. What we are also finding is that some of the patients that have gone home, wherever that might be... the Caribbean, Africa, Asia... you know; they have gone home with a debt but when they apply for another visa they are being told that they can't get it (Interview 2).

Importantly, such outstanding NHS debt can thereby also function as an effective barrier to regularisation, even where the applicants would otherwise meet all the legal requirements for their residence to be legalised under the immigration rules.

\subsubsection{Everyday Bordering Within the University}

Like access to free secondary healthcare, the admission to study at a UK university is also strictly contingent on legal residence in the country; universities themselves have to play a fundamental role in determining a foreigner's eligibility for a student visa. Before international students can even make such an application to the HO, they have to request a Confirmation of Acceptance for Studies (CAS) statement from their prospective university, which thereby officially confirms its intention to 'sponsor' the student's visa application. Only institutions holding a sponsor licence - which has to be renewed annually and can be revoked by the $\mathrm{HO}$ - can issue CAS statements and thus recruit international students. In principle, the issuing of a CAS statement is at the university's discretion, but it should be refused if a student is (or has previously been) in breach of immigration rules or if the university deems any of the documents submitted or declarations made by the student to be fraudulent. According to the Immigration Policy and Guidance Manager of a medium-sized university in London, this puts a lot of pressure on institutions as well as on individual members of staff:

So we have to... get that balance right; and we won't always get it right. There will be instances where... you know, we would have said 'no' to the student when actually we might have been able to be a little bit more flexible with them. [...] So it is very difficult, and I think also the guidance that comes from the $\mathrm{HO}$ to education providers [...] about who you can and can't accept isn't always helpful. And therefore, there is a lot interpretation, and a lot of discretion, and of discrepancy across the education sector in particular, [with] people like myself having to say what this or that particular rule means (Interview 4).

She also highlights the unequal power relations between the government and public universities and thereby hints at the increasing neoliberalisation of the latter, which explains why education providers have accepted this responsibility in the first place: 
We, as a sector, are responding to the $\mathrm{HO}$ because we have to, because we need international students because it's such a big financial incentive. We have to have those students to operate, and that's the same for most universities in the UK, and so in a way any changes they make, while we will complain about them across the sector, and we will lobby for them to be slightly different, ultimately those changes will go ahead $[\ldots]$ and we will have to respond to them (Interview 4).

Also here, the external logic of (internalised) immigration control not only conflicts but also partly overlaps with the university's own functional logic and imperatives, as my interviewee pinpoints in the following statement:

\begin{abstract}
We don't have that many obligations that are border-control-like. We just need to know that the students we have got here should be here, and everything else is what you would expect to do as a normal university anyway; you know, check whether your students are attending classes... that's not about immigration control, that's about your students getting what they are paying for. [...] They have the right that, if they are not attending classes, somebody knows that and somebody is asking why and so that kind of overlap between good pastoral care and regulating university life and $\mathrm{HO}$ intelligence is... you know, there is a bit of a blurred line with that, I think (Interview 4).
\end{abstract}

From her perspective, this only becomes problematic where immigration rules are in direct conflict with the academic assessment of a prospective student's suitability for a particular course: 'The academic department might say 'we really want that student', but we then have to say whether or not we are able to sponsor them for a visa, and if we can't then obviously we can't go ahead with the process'. She also noted that such situations are 'often difficult for students to understand, and academic colleagues as well, because they are only interested in the academic situation' (Interview 4). This ultimately reflects the fact that academic staff are much more shielded from any control responsibility beyond the academic, as a lecturer of another university emphasised:

The government is outsourcing immigration control to a whole variety of people [...and that] certainly increases the workload, which is why [...] it's now all being done by bureaucrats; because they have to do it like that, it has to be centralised, and that makes sense to me because otherwise that would be just a pain in the neck (Interview 5).

In order for academics to do their job, somebody else has to deal with students' immigration issues in a systematic way - if not the central government then at least specially trained bureaucrats working within the university. In fact, most UK universities have already established dedicated teams of advisors who check all foreign students' eligibility and assist them with any visa issues. While these advisors are usually certified (to give immigration advice) by the Office of the Immigration Services Commissioner (OISC), they are less attached to some of the logics that otherwise dominate organisational action within universities. The way the Immigration Policy and Guidance Manager justified the role of her own team clearly indicates this:

Before my team existed, these decisions might have been taken by different colleagues depending on who is involved, so it might have been the academic department even... And so there was room for different decisions based on personalities, and there was no record of those decisions, it was a bit... of a mess [... because] there is not so much awareness of the 
actual technicalities and the rules and so on, you know. [...] I wouldn't expect admissions to understand that necessarily, because their job is to process an application and an academic's job is to teach (Interview 4).

Crucial to my analysis is that also here, one side-effect of this organisational adjustment is that part of the university administration works much more closely with the immigration authority. As my interviewee explained, her team

[h] as names and contacts at the HO [and] where we are concerned about a student's status [or] if the student is telling us things and we need more information, with the student's consent we can actually contact the HO for what's called a Student Eligibility Check (Interview 4).

What she initially describes as a mechanism through which the HO 'helps' the university to deal with complex cases, however, also puts a legal obligation on individual student advisors to inform the $\mathrm{HO}$ 'if we categorically know that somebody is in breach of their visa condition' (Interview 4). The way in which she and her team tend to handle such encounters with (potential) irregularity in practice suggests that they often struggle with this obligation:

If I'm completely honest, where we suspect that, we would, from an advisory point of view, make the student aware [...] that we would have a legal obligation... But we wouldn't... just say 'We think you are in breach' and tell the HO. We would kind of engage with the individual to try and encourage them to stop doing what we think they are doing; but ultimately, we wouldn't want to kind of police that because that puts an unrealistic kind of burden on us. [...] We did have an application once from a student who... was a failed asylum-seeker and had gone kind of underground, so to speak, and so obviously if we would have suddenly sent this student's eligibility check to the $\mathrm{HO}$ we would be flagging up that this student is here, that we have their address, we had all that information... And that doesn't... that's not what we are there to do, we are there to assess a student's ability to study with us, not to say to the HO 'we found this failed asylum-seeker and here is where they are' (Interview 4).

Ultimately, this reflects her awareness of the consequences that such information exchange with the immigration authority could potentially have for a student's stay in the country, and that immigration enforcement as such lies beyond what she perceives to be her responsibility as a university employee.

\subsubsection{Everyday Bordering Within the Local Welfare Office}

Irregular migrants living in the UK generally also have No Recourse to Public Funds (NRPF). This condition is defined under immigration legislation ${ }^{5}$ and renders them ineligible to receive any public support or benefit, including those services administered at the local level ${ }^{6}$ (NRPF Network 2018; Stephens et al. 2010). The

\footnotetext{
${ }^{5}$ In Section 115 of the Immigration and Asylum Act 1999.

${ }^{6}$ Notably, neither primary and emergency healthcare nor compulsory education are classified as 'public funds' in this respect.
} 
national legal framework only acknowledges very few and narrowly defined situations in which unlawful residents can avail themselves of publicly funded measures of social assistance and protection. One of them is where they have minor children who are assessed as destitute (or about to become destitute) and thus become eligible for support from the local authority (LA) which, under Section 17 of the Children Act 1989, has a duty to ensure the welfare of every child in need within its jurisdiction (Dorling et al. 2013; NRPF Network 2018). It is important to note that LAs are only allowed to support unlawful residents where withholding such support would result in a breach of the child's human rights. In addition, immigration law places a legal duty on LAs to inform the $\mathrm{HO}$ when unlawful residents request support from social services (NRPF Network 2018).

Where the statutory case-assessment by the LA establishes such responsibility towards a particular family, however, this usually implies a substantial financial burden. Data collected by Price \& Spencer (2015, p. 51) suggest that more than one third of accepted NRPF cases remain in LA support for between one and 3 years. Nor can LAs refuse support on the basis of insufficient municipal funds or be reimbursed by the state for these additional expenditures (NRPF Network 2018). Particularly in areas of high immigration and in the context of substantial cuts to LA budgets, this has created significant financial pressure and triggered organisational adjustments that clearly parallel what is happening in hospitals and universities: In order to deal more effectively with irregular migrants' claims, many local welfare departments established specific teams who are responsible for doing just that.

For Price \& Spencer (2015), the existence of a dedicated NRPF team constitutes one of three crucial factors that explain the significant variation in how the different LAs respond to claims for support under Section 17 of the Children Act. Specifically tasked to deal with clients identified as having No Recourse to Public Funds, these teams are particularly common within London, where the majority of families receiving so-called Section-17 support live. ${ }^{7}$ From the perspective of LAs, having such a team not only seems to favour a more consistent application of the rules and more efficient referral procedures but also allows for more effective gate-keeping, as the manager of an NRPF team was keen to emphasise:

They will only be able to get support [...] through my team, and it's only provided conditional on various other things... they have to be able to show that they are territorially the responsibility of [this borough], that they are destitute, and that they have either an on-going application with the $\mathrm{HO}$ or are imminently about to make one [...] And that's the point about having the dedicated team: that, when this function was spread across the authority's social care and health services, applicants could come in repeatedly, and [...] it was impossible to identify a scenario that had been heard before. When you have a small discrete team, you can spot patterns very, very quickly. And one of the things we do is pick up patterns of information that is out in the community [about] what worked and so other people would then come in repeating [the same story]. And we spot that much more quickly now (Interview 6.1).

\footnotetext{
${ }^{7}$ According to a countrywide survey, 1632 of 2679 families who received support during the financial year 2012/13 were registered in one of the 33 London boroughs, at least 16 of which already had established NRPF teams (Price and Spencer 2015, p. 25).
} 
That NRPF teams tend to perceive their role mainly in terms of gate-keeping rather than safeguarding and providing social care to vulnerable residents reflects the conditions under which they are being introduced. In one borough, the combined annual cost of NRPF support reached more than six million pounds by 2014 (compared to around $£ 150,000$ in the years before 2008). A review of how the council had been dealing with such cases found the overall approach to be ambiguous and ineffective. Part of the identified problem was that 'the assessment by social workers prioritises safeguarding, [...] not NRPF eligibility criteria', as stated in the official minutes of a meeting where the review results were discussed in November 2014. In order to address this deficit, a dedicated team of five specialist case-workers and one 'embedded' HO worker was set up in order to deal with all NRPF cases - about 80 per cent of which concern migrant families in irregular situations - in a more consistent way. In a background paper presented at the same meeting, this 'robust front door approach' was praised for having already 'started to have significant impact on managing spend in this area'. Whereas, prior to the new approach, more than half of all cases had been accepted for support, only one of the 96 applications that have been made since then has been successful, while eight were being supported temporarily pending full assessment. Based on the average acceptance rates of 9.7 (prior to the pilot) and 1.3 cases per month (during the pilot), another internal document calculates the annual saving to the LA at 2.2 million pounds. Quite clearly, shifting the responsibility of carrying out initial case assessments from social workers to administrative staff (who, in this case, are directly supported by a HO worker) has altered the dominant logic driving the assessment itself. As one NGO practitioner put it, within NRPF teams

there can be a bit of a culture of looking at the immigration status first, or looking at the adults and I think, because it's not part of social services, you don't get such a child-centred approach, so they are not really looking at 'Is this child in need and what are the needs of this child?'; they are looking at 'Well this adult overstayed their visa or this adult is somehow to blame' and, you know, trying to allocate blame or deciding who is deserving is not the correct test (Interview 1).

Also Price and Spencer's (2015, p. 47) study suggests that those NRPF teams which consist mainly of case-workers rather than social workers 'tended to conceive of their duties to these families as administrative tasks'. One such administrative function of NRPF teams precisely consists in linking local social service departments even closer to the HO which - in the eyes of a social worker I interviewed (together with the NRPF manager) - reflects the overlapping interests of both organisations:

I do think that there has been, over the last few months, a change from the $\mathrm{HO}$ as well, and I don't know whether or not that's the work that the No Recourse Team has been doing, because they are much more open to us. We had a visit, [...] they are coming and doing some training for us and we have a point of contact if we have concerns over any person, which actually is something that is practically unheard of. [...] They didn't have an opendoor-approach at all. And I think that has changed because they have seen the value of actually working much more in partnership; and we hope to build on that as well (Interview $6.2)$. 
Once again, another benefit of having a specially trained team dealing with all these cases centrally is that 'normal' social workers are thereby effectively shielded from having to apply the logic of immigration control, as the same interviewee indicated:

If we see people where we think there is some issue around their status, then actually we refer it to [the NRPF team] for them to investigate; that's where the expertise around migration is $[\ldots]$. We don't have to make those judgements (Interview 6.2).

At the same time, the fact that more and more social service departments are starting to also rely on HO case-workers 'embedded' within their NRPF teams shows that this development is not just about expertise but also about access to certain information that social services - as well as the HO - would otherwise lack, as the NRPF team manager noted:

What we found is that having an embedded [HO] worker is much more effective; because the embedded worker goes straight onto the system, is able to do a forensic analysis of what's happening. So when we have walk-ins we get the answer that minute, this person has a claim, this person doesn't have a claim, they have a long history, it has been refused so many times, or they have an outstanding appeal, or whatever. [...] And likewise, the reason the $\mathrm{HO}$ agreed to this and the reason they are now extending these options to other boroughs is because they have learned that, actually, the quality of intelligence that they get from us, about patterns more than to do with individuals, is much greater than you will get from just that kind of exchange around individual cases (Interview 6.1).

While this cooperation again seems to be driven by a mutual interest of the LA and the HO, for applicants who are not only destitute but also in an irregular situation it means an almost total overlap of both parts of the administration - the one that might be legally obliged to help them and the one that threatens to deport them. The way in which a destitute migrant mother spoke about an appointment with social services, exemplifies this:

I have to call and ask my lawyer now, because they said that... they normally would invite immigration so that immigration will threaten people... that they will take them back home... so now I have to call my lawyer to let her know...

Interviewer: So on Monday you are going to meet with your social worker and you think there will also be an immigration officer?

Yes, immigration officers. That's what they do. That's what they do to threaten... they will say that it's better for them to take you back to your country than just to leave you here without support. [...] But once I have sent the application and I have the copy of the proof of the posting, that way they can't... (Interview 7).

Her reluctance to even meet her social worker without prior advice from a lawyer says a lot about the level of trust she has in the former. Notably, the invention of NRPF teams has been crucial for establishing the intimate institutional relationship between social work and immigration enforcement that ultimately triggers this reluctance. Like other services that were originally set up as means of integration of individuals and society as a whole - social service departments now also contribute to the disintegration of irregular migrants. 


\subsection{Conclusion}

In this chapter I have discussed the role of public service provision as a site where integration and disintegration policies and practices intersect, and the resulting conflicts must be dealt with on an everyday basis. Specifically, I have looked at the implementation of explicit disintegration policies within three concrete institutions that otherwise fulfil integrative functions - namely hospitals, universities and social service departments. By becoming more or less actively involved in this implementation, these institutions and (at least some of) the individuals working within them participate in the broader politics of (dis)integration. As set out in the introduction to this volume, the latter involves the intertwining of apparently contradictory processes and thus requires a constant renegotiation of conflicting (policy) aims and related institutional logics.

The main contribution of the chapter is to show that the politics of (dis)integration can also trigger institutional change. As my analysis shows, an important structural feature that accompanies the extension of everyday bordering practices into different spheres of public service provision has been the emergence of specialised sub-units within the very organisations that provide these services to the local population. I have argued that it is precisely through OVMs, Student Immigration Advisors and NRPF teams that the state has been able to not only raise but also effectively patrol 'a protective wall [...] around the key institutions of the welfare state', as Broeders \& Engbersen (2007, p. 1595) have argued. In fact, this wall no longer merely surrounds these institutions but now runs right through them. It is important to note, however, that although these sub-divisions have come to play an important role within the 'hostile environment' approach, their creation has not been explicitly demanded by central government. Instead, it was the need to ensure their own (cost-) effective functioning that encouraged the various organisations themselves to introduce a certain element of immigration control into their institutional structures and operations. Rather than (legally enforced) deputisation, the underlying processes are thus better described as what Walsh (2014) defined as (encouraged but voluntary) responsibilisation or even (spontaneous) autonomisation.

From the perspective of organisation theory, such structural adjustments to a new set of external requirements represent a common way for organisations to avoid internal conflicts between the dominant and other logics that compete to guide their actions. Where individual actors perceive these logics as incompatible, they will struggle to incorporate the new demands into their work, which renders their deputisation inherently difficult. This is particularly true for professionals who are trained to work within a particular field and thus become the most attached to its dominant logic. Doctors, social workers or academics, for example, are more difficult to convince than reception staff that access to the service they deliver should be based on immigration status rather than medical need, apparent destitution or intellectual potential. 
Arguably, this is precisely why it makes sense (from the point of view of the organisation) to develop what Besharov \& Smith (2013, p. 376) have called 'a cadre of organisational members who are less strongly attached to particular logics' in order to more effectively deal with contradictory external demands. While this helps to buffer professionals from having to deal with these uncomfortable demands, it also means that crucial gate-keeping responsibilities are transferred from trained professionals to untrained administrators or even very differently trained immigration officers. These insights hopefully contribute to a better understanding of how internal immigration control works within the different spheres of public welfare and why the pressure to exclude irregular residents will not necessarily reduce their number but the ability of public institutions to fulfil their primary function for society as a whole.

\subsection{List of Interviews}

Interview 1: Case-worker and lawyer working for the organisation Project 17, 22 October 2014.

Interview 2: Head of the Overseas Department of a medium-sized NHS hospital, 31 October 2014.

Interview 3: General Practitioner (GP) at a health centre in North London, 10 November 2014.

Interview 4: Immigration Policy and Guidance Manager at a university in South London, 24 February 2015.

Interview 5: University lecturer at a university in central London, 4 February 2015.

Interview 6: NRPF service manager (6.1) and social worker (6.2), both working for the same local council in London, 26 February 2015.

Interview 7: Single mother from Nigeria, living in London since 2013, 17 February 2015.

\section{References}

Balibar, E. (1998). The borders of Europe. In P. Cheah \& B. Robbins (Eds.), Cosmopolitics: Thinking and feeling beyond the nation (pp. 216-233). Minneapolis: University of Minnesota Press.

Besharov, M. L., \& Smith, W. K. (2013). Multiple institutional logics in organizations: Explaining their varied nature and implications. Academy of Management Review, 39(3), 364-381.

Black, R. (2003). Breaking the convention: Researching the 'illegal' migration of refugees to Europe. Antipode, 35(1), 34-54.

Bommes, M., \& Geddes, A. (Eds.). (2000). Immigration and welfare: Challenging the Borders of the welfare state. London/New York: Routledge. 
Boswell, C. (2007). Theorizing migration policy: Is there a third way? International Migration Review, 41(1), 75-100.

Broeders, D., \& Engbersen, G. (2007). The fight against illegal migration: Identification policies and immigrants' counterstrategies. American Behavioral Scientist, 50(12), 1592-1609.

Carens, J. (2013). The ethics of immigration. New York: Oxford University Press.

Castles, S. (2004). Why migration policies fail. Ethnic and Racial Studies, 27(2), 205-227.

Chauvin, S., \& Garcés-Mascareñas, B. (2014). Becoming less illegal: Deservingness frames and undocumented migrant incorporation. Sociology Compass, 8(4), 422-432.

Collyer, M., Hinger, S., \& Schweitzer, R. (2020). Politics of (Dis)Integration - An Introduction. In S. Hinger, \& R. Schweitzer (Eds.), Politics of (Dis)Integration (pp. 1-18). Cham: Springer VS.

Cvajner, M., \& Sciortino, G. (2010). Theorizing irregular migration: The control of spatial mobility in differentiated societies. European Journal of Social Theory, 13(3), 389-404.

Da Lomba, S. (2011). Irregular migrants and the human right to health care: A case-study of health-care provision for irregular migrants in France and the UK. International Journal of Law in Context, 7(3), 357-374.

DoH. (2012). 2012 Review of Overseas Visitors Charging Policy. London: Department of Health. Retrieved 05 July 2018 from: https://www.gov.uk/government/uploads/system/uploads/attachment_data/file/210439/Overseas_Visitors_Charging_Review_2012_-_Summary_document. pdf.

DoH. (2013a). Guidance on implementing the overseas vvisitors hospital charging regulations. London: Department of Health. Retrieved 05 July 2018 from: https://www.gov.uk/government/ publications/guidance-on-overseas-visitors-hospital-charging-regulations.

DoH. (2013b). Sustaining Services, Ensuring Fairness. A Consultation on Migrant Access and their Financial Contribution to NHS Provision in England. London: Department of Health. Retrieved 05 July 2018 from: https://assets.publishing.service.gov.uk/government/uploads/ system/uploads/attachment_data/file/210438/Sustaining_services_ensuring_fairness_consultation_document.pdf.

Dorling, K., Bolton, S., Barrett, J., Compton, R., East, A., Freeman, S., Hurrell, A., Smallwood, D., \& Brzezina, D. (2013). Growing up in a hostile environment: The rights of undocumented migrant children in the UK. Colchester: Children's Legal Centre (CORAM). Retrieved 05 July 2018 from: https://www.childrenslegalcentre.com/growing-hostile-environment/.

Ellermann, A. (2006). Street-level democracy: How immigration bureaucrats manage public opposition. West European Politics, 29(2), 293-309.

FRA. (2013). Apprehension of migrants in an irregular situation: Fundamental rights considerations. Vienna: European Union Agency for Fundamental Rights.

Garcés-Mascareñas, B. (2015). Revisiting bordering practices: Irregular migration, borders, and citizenship in Malaysia. International Political Sociology, 9(2), 128-142.

Guiraudon, V., \& Lahav, G. (2000). A reappraisal of the state sovereignty debate: The case of migration control. Comparative Political Studies, 33(2), 163-195.

Hellgren, Z. (2014). Negotiating the boundaries of social membership: Undocumented migrant claims-making in Sweden and Spain. Journal of Ethnic and Migration Studies, 40(8), $1175-1191$.

Hinger, S. (2020). Integration through disintegration? The distinction between deserving and undeserving refugees in national and local integration policies in Germany. In S. Hinger, \& R. Schweitzer (Eds.), Politics of (Dis)Integration (pp. 19-39). Cham: Springer VS.

Home Office. (2013). Immigration bill factsheet: Overview of the bill. London: Home Office. Retrieved 05 July 2018 from: https://www.gov.uk/government/uploads/system/uploads/attachment_data/file/249251/Overview_Immigration_Bill_Factsheet.pdf.

Jordan, B., Stråth, B., \& Triandafyllidou, A. (2003). Contextualising immigration policy implementation in Europe. Journal of Ethnic and Migration Studies, 29(2), 195-224.

Kirkup, J., \& Winnett, R. (2012). Theresa may interview: 'We're going to give illegal migrants a really hostile reception', The Telegraph, 25 May. Retrieved 05 July 2018 from: http://www. 
telegraph.co.uk/news/uknews/immigration/9291483/Theresa-May-interview-Were-going-togive-illegal-migrants-a-really-hostile-reception.html.

Lahav, G., \& Guiraudon, V. (2006). Actors and venues in immigration control: Closing the gap between political demands and policy outcomes. West European Politics, 29(2), 201-223.

Lindberg, K. (2014). Performing multiple logics in practice. Scandinavian Journal of Management, 30(4), 485-497.

Lipsky, M. (1980). Street-level bureaucracy: The dilemmas of the individual in public service. New York: Russell Sage Foundation.

Lipsky, M. (1987). Street-level bureaucrats as policy makers. In D. L. Yarwood (Ed.), Public administration, politics, and the people: Selected readings for managers, employees, and citizens (pp. 121-127). London: Longman.

Luhmann, N. (1982). The differentiation of society. Columbia: Columbia University Press.

Luhmann, N. (1995). Social systems. Stanford: Stanford University Press.

Meyer, J. W., \& Rowan, B. (1977). Institutionalized organizations: Formal structure as myth and ceremony. American Journal of Sociology, 83(2), 340-362.

MRN. (2015). Briefing on the proposed immigration bill 2015-16. London: Migrants' Rights Network. Retrieved 05 July 2018 from: https://www.migrantsrights.org.uk/wp-content/ uploads/publications/MRN_Immigration_Bill_Briefing_2015-v1.pdf.

NRPF Network (2018). Assessing and supporting children and families who have no recourse to public funds (NRPF). Practice Guidance for Local Authorities. Retrieved 05 July 2018 from: http://guidance.nrpfnetwork.org.uk/reader/practice-guidance-families/.

OHCHR. (2014). The economic, social and cultural rights of migrants in an irregular situation. In Office of the United Nations High Commissioner for Human Rights. New York/Geneva.

Park, J. S. W. (2013). Illegal migrations and the huckleberry Finn problem. Philadelphia: Temple University Press.

Perna, R. (2018). Bound between care and control: Institutional contradictions and daily practices of healthcare for migrants in an irregular situation in Italy. Ethnic and Racial Studies (online first), 1-20. https://doi.org/10.1080/01419870.2018.1533645.

Price, J., \& Spencer, S. (2015). Safeguarding children from destitution: Local authority responses to families with 'no recourse to public funds. Oxford: University of Oxford, COMPAS Report. Retrieved 05 July 2018 from: www.compas.ox.ac.uk/research/welfare/nrpf/.

Reay, T., \& Hinings, C. R. (2009). Managing the rivalry of competing institutional logics. Organization Studies, 30(6), 629-652.

Schweitzer, R. (2017a). Integration against the state - The state against integration? Politics blog. Retrieved 05 July 2018 from: http://politicsblog.ac.uk/2017/02/05/ integration-state-state-integration/.

Schweitzer, R. (2017b). Integration against the state: Irregular migrants' agency between deportation and regularisation in the United Kingdom. Politics, 37(3), 317-331.

Schweitzer, R. (2018a). The micro-Management of Migrant Irregularity and its control : A qualitative study of the intersection of public service provision with immigration enforcement in London and Barcelona. Brighton: University of Sussex, $\mathrm{PhD}$ thesis.

Schweitzer, R. (2018b). Health care versus border care: Justification and hypocrisy in the multilevel negotiation of irregular migrants' access to fundamental rights and services. Journal of Immigrant and Refugee Studies (online first), 17, 61-76. https://doi.org/10.1080/15562948.2 018.1489088.

Sciortino, G. (2000). Toward a political sociology of entry policies: Conceptual problems and theoretical proposals. Journal of Ethnic and Migration Studies, 26(2), 213-228.

Scott, W. R. (2001). Institutions and organizations. Los Angeles: Sage.

Scott, W. R., Ruef, M., Mendel, P. J., \& Caronna, C. A. (2000). Institutional change and healthcare organizations: From professional dominance to managed care. Chicago: University of Chicago Press.

Spencer, S., \& Hughes, V. (2015). Outside and in: Legal entitlements to health care and education for migrants with irregular status in Europe. Oxford: University of Oxford, COMPAS Report. 
Squire, V. (2011). The contested politics of mobility. Politicizing mobility, mobilizing politics. In V. Squire (Ed.), The contested politics of mobility. Borderzones and irregularity (pp. 1-25). London: Routledge.

Stephens, M., Fitzpatrick, S., Elsinga, M., van Steen, G., \& Chzhen, Y. (2010). Study on housing exclusion: Welfare policies, labour market and housing provision. Brussels: European Commission.

Treibel, A. (2015). Integriert Euch! Plädoyer für ein selbstbewusstes Einwanderungsland. Frankfurt/New York: Campus Verlag.

Van der Leun, J. (2006). Excluding illegal migrants in the Netherlands: Between national policies and local implementation. West European Politics, 29(2), 310-326.

Walsh, J. P. (2014). Watchful citizens: Immigration control, surveillance and societal participation. Social and Legal Studies, 23(2), 237-259.

Walzer, M. (1983). Spheres of justice: A defense of pluralism and equality. New York: Basic Books. Webb, J. (2006). Organisations, identities and the self. Basingstoke: Palgrave Macmillan.

Wind-Cowie, M., \& Wood, C. (2014). Do no harm. Ensuring fair use of the NHS efficiently and effectively. London: DEMOS. Retrieved 05 July 2018 from: http://demos.co.uk/files/Demos_ DoNoHarmREPORT.pdf?1413823102.

Open Access This chapter is licensed under the terms of the Creative Commons Attribution 4.0 International License (http://creativecommons.org/licenses/by/4.0/), which permits use, sharing, adaptation, distribution and reproduction in any medium or format, as long as you give appropriate credit to the original author(s) and the source, provide a link to the Creative Commons licence and indicate if changes were made.

The images or other third party material in this chapter are included in the chapter's Creative Commons licence, unless indicated otherwise in a credit line to the material. If material is not included in the chapter's Creative Commons licence and your intended use is not permitted by statutory regulation or exceeds the permitted use, you will need to obtain permission directly from the copyright holder.

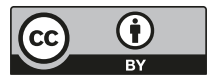

